\title{
Una mirada crítica sobre la medicina en el Antiguo Egipto
}

\author{
Walter Ledermann
} Centro de Estudios Humanistas
Julio Prado. Santiago, Chile.

Recibido: 18 de noviembre de 2016

Correspondencia a: Walter Ledermann revinf@sochinf.cl

\section{A critical regard over the medicine in the Ancient Egypt}

Generally, writing about the medicine in the Ancient Egypt, historians adopt an approach rather benevolent than critical, giving to its practice merits that never had. Reading without prejudice the famous twelve papyri -and now one more- we can't less to pronounce a condemnatory sentence, because at the end this medicine looks like a patchwork of ignorance, superstition, magic believes and a pair of grains of knowledge. However, we can rescue its surgical practice, very useful, sometimes efficient, and quite necessary in those centuries of war, slavery and permanent abuse of the weak and the poor people by the high political rulers and priests.

Key words: Ancient Egypt, medicine, surgery, papyri, Imhotep.

Palabras clave: Antiguo Egipto, medicina, cirugía, papiros.

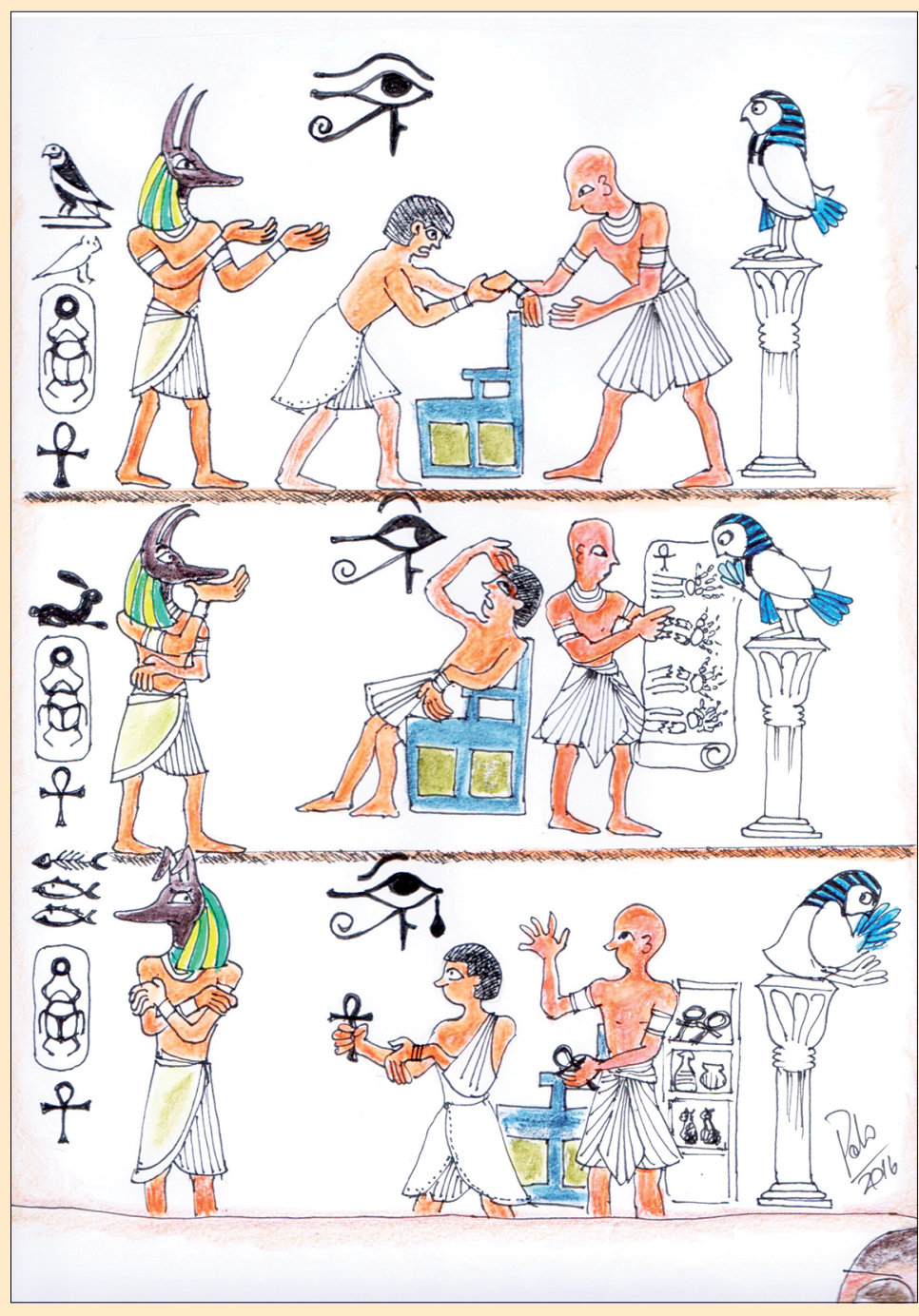

L os historiadores suelen tender un benevolente velo para ocultar la rudeza de la práctica médica en los tiempos antiguos, juzgando los usos propios de las distintas y sucesivas culturas de acuerdo a las salvajes épocas en que se desarrollaron, cuando la vida humana valía poco y, para muchos, nada. Esta postura ha llevado, sin duda, a sobrevalorar la medicina del antiguo y faraónico Egipto, atribuyendo al variopinto contenido de sus papiros médicos un valor que nunca tuvo. Porque, no nos confundamos: los papiros son valiosos como documentos históricos, que nos ilustran sobre el quehacer médico en la Antigüedad, pero el nivel que éste muestra, cuando leemos su contenido con ojo desprejuiciado, es harto pobre.

\section{Imhotep, más arquitecto que médico}

Quizás si el primer científico o médico propiamente tal, conocido y célebre, fue el astrólogo egipcio Imhotep, literalmente "uno que viene en paz", quien allá por el año 2680 antes de Cristo, fue consejero de Zoser, el primer -o quizás segundo- rey de la III Dinastía. Este Imhotep era un sabio múltiple, llegó a constituir leyenda y terminó deificado siglos después de muerto, merced a la fama ganada en vida por sus habilidades terapéuticas, que parecían mágicas. Su previsión por anticiparse a épocas de sequía, construyendo grandes graneros para almacenar trigo en los años de buenas cosechas, dio probablemente origen a la historia de José y la adivinanza de las siete vacas gordas y las siete vacas flacas saliendo del Nilo, que le habría ganado la voluntad del faraón.

Pero su verdadera especialidad o su mayor habilidad parece haber sido, no la medicina ni la magia ni la gestión política, sino la arquitectura, demostrada en la construc- 
ción del sepulcro de Zoser, la mastaba más grande hasta entonces y la primera hecha de piedra y no de ladrillo, aunque el dibujo imita la madera y la caña. El edificio fue levantado en Sakkara, con 210 pies de largo por todos sus lados y una altura de 25 . Con posterioridad el arquitecto, no contento con sus dimensiones, la amplió, dándole una base de 350 por 400 pies, colocando después encima mastabas en tamaño decreciente, para formar una torre de seis pisos, con una altura total de unos 200, rodeada por otras estructuras y todo encerrado por una alta muralla de paneles de piedra caliza: en total, una gigantesca estructura de 1.800 pies de largo y 900 de ancho. ¿Qué queda de toda esta magnificencia, que fue de tanta invención que truxeron? Los detalles artísticos finos han desaparecido, pero la torre central permanece, aunque bastante abandonada y deteriorada por un olvido de siglos, siendo la más antigua construcción humana que aun se levanta en este mundo ${ }^{1,2}$.

Imhotep, quien también era sacerdote, poeta y astrólogo, vivió bajo el reinado de otros tres faraones más, si hemos de creer en las inscripciones que lo mencionan encontradas en monumentos de estos reyes: "canciller del Rey del Bajo Egipto”, “el primero bajo el Rey”, “el administrador de la gran mansión", "el noble hereditario", "el Alto Sacerdote de Heliopolis", el "jefe escultor" y el “jefe carpintero"... ¡ ¡Le faltó ser pintor para humillar a Leonardo Da Vinci!

Aunque grandes historiadores de la medicina dicen que sus enseñanzas no están en los papiros médicos que entraremos a revisar, creemos que con seguridad lo están, al menos parcialmente, transmitidas por la tradición: total, la medicina egipcia poco parece haber progresado en miles de años. Con nosotros, Dunn afirma que el papiro de Edwin Smith, que contiene 90 términos anatómicos y 48 heridas bien descritas, sería de su autoría; que podría haber fundado una escuela de medicina en Memphis, desde donde sus discípulos habrían diseminado sus ideas ${ }^{4}$. Y todo esto 2.200 años antes del nacimiento de Hipócrates y de que los griegos crearan a su imagen su propio dios médico, Esculapio.

Terminemos el tema con las palabras de Sir William Osler $^{5}$, el gran médico norteamericano:

“...primera figura de un médico destacada claramente de las nieblas de la antigüedad, Imhotep diagnosticó y trató sobre 200 enfermedades, 15 del abdomen, 11 de la vejiga, 10 del rectum, 29 de los ojos, y 18 de la piel, cabello, uñas y lengua. Imhotep trató tuberculosis, cálculos biliares, apendicitis, gota y artritis. También hizo cirugía y practicó algo de dentística. Imhotep extrajo medicina de las plantas. También conoció la posición y función de los órganos vitales y la circulación del sistema sanguíneo". Por su parte la Enciclopedia Británica dice: "La evidencia proporcionada por textos egipcios y griegos respalda que la reputación de Imhotep era muy respetada en los primeros tiempos. Su prestigio creció en el lapso de siglos y sus templos en los tiempos de Grecia eran los centros de enseñanza médica".

\section{Los célebres papiros médicos}

En los tiempos en que ocurrían los hechos que relatamos, la vida era muy corta, estando el hombre sometido a mil peligros, de modo que las malformaciones congénitas no sobrevivían mucho, las enfermedades metabólicas no llegaban a ser crónicas y tampoco persistían las hormonales, en tanto que las oncológicas no alcanzaban a manifestarse. Enfrentando a guerras continuas, el hombre moría mayormente por traumatismos, siendo con mucha probabilidad la segunda causa las epidemias, a parejas con las hambrunas y los desastres naturales. En los papiros que pasamos a analizar se habla bastante de las heridas, pero casi nada de las infecciones. ¿Poca capacidad de observación o, simplemente, se las consideraba mágicas, castigos divinos o algo así y, por tanto, ajenas a la medicina?

Hasta hace poco se conocía una docena de estos preciosos documentos, que iremos presentando de acuerdo a su antigüedad:

El más antiguo es el papiro de Ramesseum, que podría fecharse en 1980 a. C., conservado en Oxford y llamado así por haberse encontrado en un templo consagrado al faraón Ramsés II, una mezcla heterogénea de recetas médicas y de recetas mágicas, mayoritariamente para el manejo de los miembros rígidos, pero también indicaciones de cómo separar al niño de la madre durante el parto y cómo pronosticar un embarazo y deducir el sexo del feto de acuerdo a los senos, ojos y facciones de la madre. No debe confundirse este papiro médico con otro Ramesseum, que es el denominado "dramático" y relata las fiestas de coronación del faraón Sesostris I en el 1971 a. C., y que es muchísimo más entretenido ${ }^{6}$.

A continuación se ubica el papiro de Kahoun, probablemente de 1850 a. C. o, si prefieren, de la XII Dinastía, aunque pudiera ser posterior, hasta del 1700. Fue hallado en Ilahum o Kahoun, una localidad de Egipto; se conserva en Londres, en el University Collage, y su temática es bastante amplia, incluyendo hasta aritmética y veterinaria, pero con énfasis mayoritario en ginecología y obstetricia humanas. En su primera y segunda columnas hay 17 párrafos dedicados a enfermedades femeninas, para las cuales no se indica cirugía, sino fumigaciones, pastas y otras aplicaciones vaginales, más algunas drogas a tomar. En la tercera columna hay 17 casos o pronósticos de obstetricia, similares a las que veremos en el papiro de Berlín?

En tercer lugar viene el papiro de Turín, más o menos contemporáneo de los anteriores, también guardado en Londres, y que algo dice sobre los ojos y las picaduras de serpientes. 


\section{El papiro de Ebers}

El cuarto es el más conocido, el papiro de Ebers, probablemente escrito en Tebas, allá por el 1536 a.C., y encontrado en un extraño sitio: entre las piernas de una momia en una tumba en Assasif, desde donde fue a parar a manos de Edwin Smith, quien lo compró a un mercader egipcio en 1862. Su nombre viene del sabio egiptólogo alemán George Mortiz Ebers, quien lo adquirió diez años después y lo editó como libro, en tarea conjunta con L. Stern.

Este papiro de Ebers es el más extenso entre la docena de similares encontrados hasta la fecha, midiendo 20,25 metros de largo y $30 \mathrm{~cm}$ de ancho, escrito en 108 columnas de 20 a 22 líneas cada una; es un papiro en excelente estado de conservación, que se puede admirar en la librería de la Universidad de Leipzig. Su contenido es netamente médico y constituye la mayor fuente directa de información sobre la medicina de la época en Egipto. El estudioso Ebbell separó su contenido en nueve capítulos, según las materias tratadas, partiendo por las invocaciones divinas y continuando con medicina interna, terapéuticas oftalmológica, dermatológica y de las extremidades, para terminar con diversas prescripciones. Según el mismo autor, es una recopilación de textos más antiguos de las primeras dinastías faraónicas, de modo que no es gratuito suponer algún aporte de Imhotep. Cronológicamente, este texto corresponde a la dinastía XVIII: aparece fechado en el año ocho del reinado de Amenhotep $I^{8}$. En este precioso documento histórico, al igual que en los otros, no se habla de enfermedades infecciosas, salvo algunos remedios caseros contra las pestes, muy pocos, considerando que contiene 877 recetas.

Georg Moritz Ebers, el gran egiptólogo alemán, que vivió entre 1837 y 1898, fue un personaje singular. Estudió en las conspicuas universidades de Göttingen, Berlín y Jena, graduándose en 1865 en lenguaje egipcio y antigüedades. De inmediato partió a Egipto, donde encontraría el papiro que iba a inmortalizarlo, registrando su estadía en un libro de mucho éxito, Egipto y los libros de Moisés, cuyas ventas lo convencieron de perseverar en la literatura: ya había perpetrado un atentado al buen gusto con Una princesa egipcia antes de graduarse. Designado profesor de la Universidad de Leipzig en 1870, siguió en el cargo hasta 1889 , editando en 1874 el famoso papiro y combinando sus ediciones científicas con sus ediciones literarias, de las cuales se pueden en el presente comprar por internet: Una princesa egipcia, narrada por ella durante el alza de Darío el Grande de Persia; Arachne, basada en la historia mitológica de Aracne, la tejedora que fue convertida en araña por desafiar en competencia a una diosa, y cuyo original debemos a Ovidio; y Uarda, quizás si la más popular y mejor lograda de sus novelas, que trata de una niña supuestamente de baja cuna, injuriada por una hija de Ramses durante su visita a la ciudad de los muertos, iniciando entonces una serie de aventuras que la llevan a descubrir su verdadero origen 9 .

El quinto papiro es de de Hearst, del 1500 a. C. Está en la Universidad de California y trata en especial de fracturas. Está escrito en 18 columnas, con 260 prescripciones, similares a las mostradas en el papiro de Ebers, que es de la misma época, es decir, de la XVIII Dinastía. Fue editado por G. A. Reisner y W. Wreszinski. Dirigido a médicos y cirujanos, contiene descripciones y terapéuticas tanto medicinales como quirúrgicas: recetas para la fabricación de cosméticos y el tratamiento de las fracturas, además de mordeduras y dolencias de dedos, ojos y dientes ${ }^{10}$.

\section{El papiro de Edwin Smith}

El sexto en antigüedad y segundo en valor es el de Edwin Smith, también del 1500 a. C., conservado en la Academia de Medicina de Nueva York, básicamente un texto quirúrgico, escrito en un leguaje sobrio y preciso. Tiene 22 páginas y trata de contusiones, heridas y fracturas de los huesos craneanos, en forma sistematizada. Incluye el vendaje, reducción y entablillamiento de las fracturas, así como de los cuidados de la piel, y tiene prescripciones para la fabricación de cosméticos, terminando con una receta para patología anal. Contiene ocho exorcismos para el viento y la plaga, siendo ésta la única mención de algo relacionado con las enfermedades infecciosas.

Se supone que en realidad es el más antiguo de los papiros, redactado durante las cuatro primeras dinastías, porque su gramática es propia de esa época, siendo el documento encontrado una copia muchísimo más tardía, del siglo XVII a. C. Algunos lo atribuyen derechamente a Imhotep, aunque pareciera que fueron tres los autores; sin embargo, creemos que fuese o no fuese el autor, el escriba que lo transcribió también lo modernizó, puesto que, aparte de los ocho exorcismos, las enfermedades muy poco se atribuyen a causas mágicas y el texto es casi "científico" en sus observaciones, aunque en otros párrafos luce más bien empírico.

El nombre le viene del egiptólogo norteamericano Edwin Smith, nacido en 1822, el año en que se descifraron los jeroglíficos egipcios, lo cual lo hace un predestinado, quien lo compró en Luxor en 1862 al egipcio Mustafá Agha. Smith comprendió el valor de su hallazgo e intentó traducirlo, pero parece que fracasó y nada dijo de él en vida; muerto ya, su hija lo donó a la Sociedad de Historia de Nueva York, institución que encargó su traducción a James Breasted en 1920, quien se tomó diez años para la tarea ${ }^{11}$.

De la Sociedad de Historia el precioso documento pasó al Museo de Brooklyn en 1938 y de allí a la Academia de Medicina de Nueva York diez años más tarde, exhibiéndose recientemente por cuatro meses en el Museo 
Metropolitano de Arte de la misma ciudad (2005-2006), ocasión en que el conservador del museo se lució presentando una nueva versión inglesa, repartida con el catálogo de la exposición. Leyendo esta versión, vemos cómo los pasos que seguía la historia clínica son parecidos a los actuales, de acuerdo a este ejemplo:

1. Síntomas (y signos): espasmos, inmovilidad desde las cervicales, ojos enrojecidos.

2. Diagnóstico: fractura al nivel del cuello.

3. Veredicto (diagnóstico): enfermedad que no conozco. ¡Un médico honesto y un ejemplo a seguir por muchos colegas actuales!

4. Tratamiento: puede consultar a un mago, pues no le hará ningún mal. ¡Ya tenemos la medicina alternativa!

Finalmente, en este valioso libro encontramos algo sobre enfermedades infecciosas: un conjuro mágico contra la pestilencia. Y, para las damas, una prescripción muy moderna para curar arrugas utilizando urea, sustancia que todavía se utiliza en cremas para la cara ${ }^{12}$.

\section{Doce papiros y uno más}

El séptimo es el papiro de Erman (1450-1350), depositado en el Museo de Berlín, un tratado de magia más que de medicina, con invocaciones para lograr un embarazo y partos adecuados, con un recién nacido saludable. Muchos historiadores no lo incluyen en la lista.

En octavo lugar tenemos el papiro de Londres, perteneciente al Museo Británico. Dataría del 1350 a. C. y es otro que entrega, revueltas y al mismo nivel, recetas médicas y mágicas, siendo las más saludables estas últimas: al menos, no dañan. Es un palimpsesto muy mal conservado.

El noveno es el papiro de Berlín, escrito alrededor del 1300 a. C. Conocido también como el "libro del corazón" por contener algunos rudimentos de cardiología, aunque en general repite lo dicho en el de Ebers ${ }^{13}$.

El décimo es el papiro de Chester Berry, escrito aproximadamente entre o desde el 1330 al 1070 a. C., XIX Dinastía, también en el Museo Británico. Su nombre proviene de Alfred Chester Betty, quien lo encontró en una excavación en Deir el Medina en 1928, siendo editado por A. H. Gardiner. Contiene y repite las mismas recetas médicas y mágicas de los documentos anteriores. También algunos lo mencionan como el "Libro de los sueños". Es pequeñito, de unos $34,5 \mathrm{~cm}$ de alto, con escritura hierática, y de medicina tiene harto poco, casi es pura literatura: apenas una lista de sueños y de su interpretación, como anticipando a Freud ${ }^{14}$.

El undécimo es el papiro de Carlsberg VIII, data del 1.200 a. C., está en Copenhague y es un libro especializado en obstetricia y oftalmología.

Suele citarse como duodécimo de la lista al papiro de Leiden, que es muy reciente, de apenas unos 250 años a. C., de manera que poco aporta al conocimiento de la medicina de lo que llamamos Antiguo Egipto ${ }^{15}$.

Recientemente se encontró un décimo tercero, que es el mayor después del Ebers, pues tiene unos siete metros de largo. Está escrito por las dos caras y por dos escribas distintos: el primero escribió con pequeños caracteres un texto denso sobre algunas enfermedades y sus remedios, allá por los reinados de Tutmosis III o Amenofis II, es decir, entre 1479 y 1401 a. C; y el segundo escribió al reverso, con caracteres más amplios y perfiles marcados, descripciones más amplias y numerosas de enfermedades y sus mágicos y divinos remedios, unos 150 años más tarde (¿habría escasez de papiro o quiso glosar el texto anterior?), hacia el comienzo del reinado de Ramsés, entre el 1294 y el 1250 a. C. Su procedencia es misteriosa: un particular lo compró en Egipto en 1953 ...ं a quién y cómo?... y a su muerte la farmacéutica Ipsen lo remató, para cederlo luego al gobierno francés en la módica suma de 670.000 euros, ínfimo valor si se lo compara con el precio de transferencia de cualquier futbolista ${ }^{16}$.

Esta misteriosa aparición de un gran papiro en pleno siglo XXI nos hace recordar similares y recientes hallazgos de textos inéditos de grandes escritores, como el París en el siglo $X X$, no publicado en vida por Julio Verne, recientemente editado, traducido y difundido en todo el mundo, con grandes utilidades editoriales. ¿Por qué no lo publicó el autor ? Como además el texto era de baja calidad, indigno del célebre escritor francés, surgieron muchas dudas: cuando salió a la luz una segunda novela inédita de Verne, la carcajada fue general. También ha aparecido una primicia de Conan Doyle, guardada por años en un baúl... ¿Empezarán a aparecer ahora más papiros médicos en manos de comerciantes egipcios, cuyos tatarabuelos los adquirieron hace siglos sin saber qué eran?

La somera revisión de estos doce papiros nos hace pensar que han sido, primero, poco leídos, porque distintos artículos y distintos autores nos hablan de distintas temáticas para un mismo papiro; $\mathrm{y}$, segundo, bastante sobrevalorados, pues muestran más bien una concepción mágica de la medicina, con escasas observaciones valiosas, constituyendo una graciosa y variopinta mezcla supersticiones, con escasos conceptos de medicina práctica. Y, lo que es peor para nosotros, los infectólogos, nada de enfermedades infecciosas, ni siquiera una alusión a las “miasmas", que tan populares se harían en la Edad Media.

\section{La paleopatología rescata las enfermedades infecciosas}

Sin embargo, las enfermedades infecciosas existían en aquellos años, como lo prueba la ya mencionada paleopatología, del griego paleo, viejo, y pathos, sufrimiento, término creado por Shufeldt en 1882 "la ciencia de las 
condiciones patológicas presentes en los órganos de los animales extintos y petrificados". El gran paleopatólogo M. A. Ruffer (1859-1917), cuyos hallazgos en Egipto pasamos a mostrar, mejoró la definición como la ciencia de las enfermedades que pueden ser demostradas en restos humanos procedentes de épocas remotas, cuyas fuentes son restos óseos y momias, y sus métodos la microscopia, radiología, serología, estadística, genética.

En el período que va del 2850 a. C. al 640 d. C., Egipto dejó una rica fuente de información paleomédica, ya que momificaban a sus muertos, dejando unos seis mil esqueletos. Así podemos ahora saber de la existencia de varias enfermedades infecciosas, cuyas huellas muestran los cadáveres tan celosamente conservados: Har-mosé, cantante natural de Nut, XV a. C., muestra una neumonía inferior derecha, y una anciana nubia del siglo $\mathrm{X}$ a. C., un empiema enquistado, probablemente caseoso, es decir, tuberculoso. También se han encontrado, mediante tinción de Gram, bacterias Gram positivas y Gram negativas en pulmones de los siglos XV-X a. C. Y también se ha encontrado abscesos renales del 1500 a. C., con bacterias incluidas; huevos de esquistosomas en uréteres; $y$ del año 1000 a. C., bacterias en riñones, un absceso perineal en una vieja sacerdotisa de Amón y en varios en hígados; mal de Pott, tuberculoso, en el infortunado sacerdote Nespe-re-han, quien falleciera alrededor del $1050 \mathrm{a}$. C.

Retrocediendo en el tiempo hasta el 3000 a. C., una radiografía de cráneo, tomada en el siglo XX d.C. a la momia de una mujer adulta, muestra la existencia de piorrea. Otra radiografía de cráneo predinástico, tomada por Elliot Smith y Dawson en 1924, permite ver claramente la destrucción de la apófisis mastoidea derecha a consecuencias de una inflamación purulenta, seguramente del oído.

En Deir el Bahari, al oeste de Luxor, entonces un suburbio de Tebas, Buffer encontró en 1921 claras señales de viruela en un colgajo de piel del muslo derecho de la momia de un hombre de mediana edad, quien habría vivido durante la XVIII dinastía ${ }^{17,18}$.

Las momias contaron lo que los escribas de los papiros callaron. Si había bacterias, había infecciones y epidemias, y nos preguntamos si entre las diez plagas de Egipto no andaría un microbio, ya que este término suele ser equivalente de peste, y éste, a su vez, se reserva en ocasiones para la bubónica. Pero la única referencia sobre las plagas es la bella fábula registrada en la Biblia, que dejaremos para otra ocasión.

\section{¿Cuánto vale, entonces, la medicina de Imhotep?}

Dejando de lado que la medicina del Antiguo Egipto parece haberse preocupado poquísimo de las enfermedades infecciosas, lo que podría influenciar nuestro juicio, analicemos brevemente lo que tenemos, para emitir una sentencia.

\section{- Una medicina ni racional ni progresiva}

Sigerist, el padre de la historia médica, sostiene que la medicina del Antiguo Egipto pasó de una primera etapa mágica y religiosa a una empírica y racional ${ }^{19}$. Disentimos de esta afirmación apoyándonos en una autoridad como Laín Entralgo, quien dice que los médicos egipcios jamás tuvieron una explicación racional de la patología y sus ideas nunca pasaron de ser lo que en su comienzo fueron: sólo rudimentarios y parciales esbozos de explicación racional $^{20}$. Y, de hecho, entre el primer papiro hasta el penúltimo, que corresponden realmente al Antiguo Egipto, hay siete siglos y ningún progreso.

\section{- Una medicina retrasada en relación a las otras artes}

Contrastando con el desarrollo de la arquitectura, donde también destacó Imhotep y por ello lo usamos como ejemplo, el avance de la medicina nos parece más bien pobre: basta comparar la magnífica mastaba que nos dejó con su herencia médica, consistente en la técnica para reducir la luxación del maxilar inferior. Y resultaría abusivo referirse a maravillas como la Esfinge y las Pirámides, quizás si irreproducibles con la técnica actual, o a las ciudades elevadas cuando muchos pueblos en el mundo vivían en chozas.

\section{- Una medicina que ofrece la magia como alternativa legítima}

En los casos clínicos registrados en los papiros suelen aparecer tres alternativas terapéuticas: medicamentos (ungüentos o infusiones de yerbas), invocaciones mágicas o divinas (había varios dioses patrocinando la medicina) y una combinación de las dos anteriores. Sin comentarios.

\section{- Una confusión entre el valor histórico de los papiros y su valor médico}

Aquí llegamos al meollo del asunto: una confusión que lleva a una sobrevaloración, pues si en un papiro milenario encontráramos el diseño de un bote mal podríamos considerarlo propio de una navegación avanzada.

\section{Resumen}

Creemos que, con mucha benevolencia, los historiadores médicos sobrestiman la medicina del Antiguo Egipto, elevando a la categoría de arte o de ciencia una práctica que más tenía de magia. Y, hablando de ella, llama la atención que ésta es bien rara en los papiros más antiguos, donde hay más medicina que superstición, aumentando los conjuros y las invocaciones a medida que más recientes 
son los documentos encontrados, quizás porque el gremio médico, al ver que los conocimientos terapéuticos empezaban a difundirse entre la masa, quiso mantener la exclusividad de ellos, agregando a la administración de los remedios físicos un ritual misterioso y esotérico, dotando así al ejercicio médico de una raíz sagrada: la magia conserva su encanto hasta la actualidad y hasta los más ilustrados creen en curaciones milagrosas.

Sólo son rescatables los aspectos quirúrgicos. El desarrollo de la cirugía y de algunas especialidades que la emplean, como la obstetricia y ginecología, respondía seguramente a la época que se vivía entonces, donde la guerra, la opresión, el abuso y la brutalidad reinantes, favorecían la génesis de heridas, traumas, quemaduras, abortos y accidentes varios, haciendo imperativo su tratamiento rápido y oportuno.

\section{Referencias bibliográficas}

1.- Encyclopaedia Britannica. Imhotep (Egyptian architect, physician and statesman). Britannica.com.

2.- Seele K C. Egypt: Ancient civilization. En: Collier's Encyclopedia. Crowell Collier and MacMillan, Inc.,1967; 8: 652-74.

3.- Asimov I. Historia de los egipcios. Dorian Press, Baltimore 1988.

4.- Dunn J. Imhotep, doctor, architect, high priest, scribe and vizier to king Djoser. www.touregypt.net/featurestories/ imhotep.htm.

5.- Barondess J. Is Osler dead? Persp Biol Med 2002, 45 (1): 65-84.

6.- Kurt Sethe (1928). Dramatische Texte zu Altaegyptischen
Mysterienspielen, II. Der dramatische Ramesseum-papyros: Ein Speil zur Thronbesteigung des Königs. J. C. Hinrichs. p. 81-264.

7.- Callender G. El renacimiento del Reino Medio (c. 2055-1650 a. C.). En Shaw, Ian. Historia Oxford del Antiguo Egipto. La Esfera de los Libros, S.L., 2000.

8.- Ebbell B. The papyrus Ebers. The greatest Egyptian Medical document. Copenhagen, Levin \& Munksgaard, 1937.

9.- Ruthven Todd. Ebers, Georg Moritz. Collier's Encyclopedia, Crowell Collier and MacMillan, Inc, USA 1967; 8: 504.

10.- Hickey T M, O’Connell E. The Hearst Medical Papyrus. CPT (Center for the Tebtunis Papyri). Bancroft Library, University of California, Berkeley, 2003.

11.- Vargas A, López M, Lillo C, Vargas M J. El papiro de Edwin Smith y su trascendencia médica y odontológica. Rev Med Chile 2012; 140: 1357-62.

12.- Allen J P. The art of medicine in Ancient Egypt. The Metropolitan Museum of Art, N. York 2006.

13.- Ghalioungui P. La medicina del Egipto faraónico. En: Lain Entralgo, P. Editor, Historia Universal de la Medicina. Barcelona, España: Salvat Editores; 1972. p. 124. 3.

14.- Jonckheere F. Le papyrus médical Chester Beatty. Fondation Egyptologique Reine Elisabeth. Bruselas 1947.

15.- Ghalioungui P. Magic and medical science in Ancient Egypt- Barnes \& Noble 1965.

16.- N.N. Cultura. El Louvre adquiere el segundo papiro médico egipcio más largo del mundo. El País (Madrid) 6/7/2011.

17.- Ruffer M A (Sir). Studies in palopathology of Egypt. Edited by Roy L. Moodie. Chicago University of Chicago Press, 1921.

18.- Shaw J. Historia Oxford del Antiguo Egipto. La esfera de los libros, S.L. 2000

19.- Sigerist H E. Ancient Egypt. In: A History of Medicine. Vol I, New York, 1951.

20.- Laín Entralgo P. Historia de la medicina. Salvat Editores S. A., Barcelona 1978. 